\title{
COMMENTARY
}

\section{Should heparin-binding protein levels be routinely monitored in patients with severe sepsis and septic shock?}

\author{
Michal Holub* and Ondřej Beran \\ See related research by Linder et al., http://ccforum.com/content/16/3/R90
}

\begin{abstract}
Heparin-binding protein (HBP), also known as azurocidin, has multiple functions in the inflammatory process, especially during severe infections. Beside its antimicrobial properties, HBP may induce vascular leakage leading to extravascular efflux, which is an important pathophysiologic event in the development of septic shock. Not surprisingly, high HBP plasma levels are found in severe sepsis patients and in septic shock patients as well as in serious infections associated with endothelial damage. In the present issue of Critical Care, Linder and colleagues demonstrate new aspects of HBP daily monitoring in ICU patients. The authors observed that high HBP plasma levels are associated with an increased mortality rate in both septic and nonseptic critically ill patients, indicating that HBP may be a reliable prognostic biomarker. However, there are some limitations hindering rapid translation of these interesting findings into the daily routine. First, the group of nonseptic critically ill patients ( $n=28$ ) enrolled in the study was rather small as compared with the septic group $(n=151)$. Moreover, $50 \%$ of nonseptic patients developed infection while hospitalized in the ICU, and to classify them as truly nonseptic patients is problematic. Second, there is a lack of a routine diagnostic method for HBP analysis. Nevertheless, if the results of the present study are validated in large clinical trials in different ICU populations and cost-effectiveness data become available, the serial HBP measurements will have a promising future.
\end{abstract}

${ }^{*}$ Correspondence: michal.holub@lf1.cuni.cz

Department of Infectious and Tropical Diseases, First Faculty of Medicine, Charles University in Prague and Na Bulovce Hospital, Budínova 2, 18081 Praha 8, Czech Republic
In the present issue of Critical Care, Linder and colleagues present a new study in which they assess the clinical importance of serial measurements of heparin-binding protein (HBP) plasma levels in critically ill septic and nonseptic patients [1]. They found that HBP plasma levels are significantly higher in patients with severe sepsis and septic shock in comparison with patients with a nonseptic critical condition. The authors also demonstrated that HBP plasma levels obtained at admission to the ICU and during the last individual sampling are higher in nonsurvivors as compared with survivors in both the septic group and the whole study group. Moreover, the high baseline HBP plasma levels in septic patients were associated with an increased 28-day mortality rate. Altogether, these results indicate that serial HBP measurements might be very helpful in stratification of ICU patients. However, there are some issues that should be raised before the study results can be translated into the daily routine.

The study was designed to compare HBP plasma levels in patients with severe sepsis and septic shock with levels in patients with noninfectious critical illness. However, these two groups of patients were not equal in size. Also, a significant proportion of patients from the nonseptic group developed infection and was treated with antibiotics. This raises the question of whether the comparison between septic and nonseptic ICU patients is hindered by this treatment. Nevertheless, the study design is logical because finding a biomarker that would predict development of any shock state is highly desirable. Previous studies have demonstrated significant predictive values of elevated levels of lactate, cortisol and IL- 6 in the blood of patients with different etiologies of shock [2-4]. However, these biomarkers have some limitations: lactate levels are less influenced by arterial sampling, endogenous cortisol levels are downregulated by corticosteroids used in the treatment of septic shock or by relative adrenal insufficiency, and IL-6 analysis is not generally available in regular hospital laboratories [5]. 
Other routinely measured biomarkers - such as procalcitonin, C-reactive protein, neutrophil and lymphocyte counts - have only a limited value in prognostic scoring of the critically ill patients and are mostly used in the early diagnostics of bacterial etiology of critical illness [6-8].

It is worth noting that HBP mediates multiple actions during the infectious process. Notably, HBP has antibacterial activity, which includes a direct microbicidal effect, and also helps neutrophils to migrate into the focus of infection. Similarly to HBP, C-reactive protein and IL-6 play an active role during the immune responses against infections: C-reactive protein is an inflammation opsonin, and the major function of IL-6 is amplification as well as downregulation of inflammatory reactions, depending on the concentrations $[9,10]$. Regarding procalcitonin, there are only limited data from animal studies - which demonstrate that immunoneutralization of procalcitonin improved survival in experimental porcine sepsis [11]. Additionally, elevated cortisol levels in peripheral blood during sepsis are considered an integral part of compensatory anti-inflammatory response syndrome, leading to downregulation of exaggerated systemic immune responses [12]. From the functional point of view, in comparison with the abovementioned biomarkers, HBP therefore plays the most complex role in severe sepsis and septic shock - highlighting its potential for clinical use.

In conclusion, the serial measurements of HBP plasma levels can be a useful tool for close monitoring of critically ill septic patients. The results of Linder and colleagues therefore warrant evaluation in different ICU populations. However, availability of a routine diagnostic method for HBP analysis is essential to confirm these interesting data.

\section{Abbreviations}

HBP, heparin-binding protein; IL, interleukin.

\section{Competing interests}

The authors declare that they have no competing interests.

\section{Acknowledgements}

The authors thank Dr E David McIntosh (Imperial College, London, UK) for help with the manuscript.

Published: 28 June 2012

\section{References}

1. Linder A, Åkesson P, Inghammar P, Treutiger CJ, Linnér A, Sundén-Cullberg J: Elevated plasma levels of heparin-binding protein in intensive care unit patients with severe sepsis and septic shock. Crit Care 2012, 16:R90.

2. Mavrić Z, Zaputović L, Zagar D, Matana A, Smokvina D: Usefulness of blood lactate as a predictor of shock development in acute myocardial infarction. Am J Cardiol 1991, 67:565-568.

3. Annane D, Sébille V, Troché G, Raphaël JC, Gajdos P, Bellissant E: A 3-level prognostic classification in septic shock based on cortisol levels and cortisol response to corticotropin. JAMA 2000, 283:1038-1045.

4. Hack CE, De Groot ER, Felt-Bersma RJ, Nuijens JH, Strack Van Schijndel RJ, Eerenberg-Belmer AJ, Thijs LG, Aarden LA: Increased plasma levels of interleukin-6 in sepsis. Blood 1989, 74:1704-1710.

5. Moran JL, Chapman MJ, O'Fathartaigh MS, Peisach AR, Pannall PR, Leppard P: Hypocortisolaemia and adrenocortical responsiveness at onset of septic shock. Intensive Care Med 1994, 20:489-495.

6. Oberhoffer M, Vogelsang H, Russwurm S, Hartung T, Reinhart K: Outcome prediction by traditional and new markers of inflammation in patients with sepsis. Clin Chem Lab Med 1999, 37:363-368.

7. Gibot S, Cravoisy A, Kolopp-Sarda MN, Béné MC, Faure G, Bollaert PE, Levy B: Time-course of sTREM (soluble triggering receptor expressed on myeloid cells)-1, procalcitonin, and C-reactive protein plasma concentrations during sepsis. Crit Care Med 2005, 33:792-796.

8. de Jager CP, van Wijk PT, Mathoera RB, de Jongh-Leuvenink J, van der Poll T, Wever PC: Lymphocytopenia and neutrophil-lymphocyte count ratio predict bacteremia better than conventional infection markers in an emergency care unit. Crit Care 2010, 14:R192.

9. Volanakis JE: Human C-reactive protein: expression, structure, and function. Mol Immunol 2001, 38:189-197.

10. Scheller J, Chalaris A, Schmidt-Arras D, Rose-John S: The pro- and antiinflammatory properties of the cytokine interleukin-6. Biochim Biophys Acta 2011, 1813:878-888.

11. Wagner KE, Martinez JM, Vath SD, Snider RH, Nylén ES, Becker KL, Müller B, White JC: Early immunoneutralization of calcitonin precursors attenuates the adverse physiologic response to sepsis in pigs. Crit Care Med 2002, 30:2313-2321.

12. Munford RS, Pugin J: Normal responses to injury prevent systemic inflammation and can be immunosuppressive. Am J Respir Crit Care Med 2001, 163:316-321.

doi:10.1186/cc11379

Cite this article as: Holub M, Beran O: Should heparin-binding protein levels be routinely monitored in patients with severe sepsis and septic shock? Critical Care 2012, 16:133. 